\title{
The impact of rifaximin in the prevention of bacterial infections in cirrhosis
}

\author{
M. MARIANI', V. ZUCCARO', S.F.A. PATRUNO', L. SCUDELLER², \\ P. SACCHI', A. LOMBARDI', M. VECCHIA ${ }^{1}$, P. COLUMPSI', \\ P. MARONE ${ }^{3}$, G. FILICE' ${ }^{1}$, R. BRUNO ${ }^{1,4}$
}

'Department of Infectious Diseases, Fondazione IRCCS Policlinico San Matteo, Pavia, Italy

${ }^{2}$ Biostatistic Unit Fondazione IRCCS Policlinico San Matteo, Pavia, Italy

${ }^{3}$ Microbiology and Virology Unit, Fondazione IRCCS Policlinico San Matteo, Pavia, Italy

${ }^{4}$ Department of Medical, Surgical, Diagnostic and Pediatric Science, University of Pavia, Pavia, Italy

\begin{abstract}
OBJECTIVE: Bacterial infections are a leading factor in the progression from compensated to decompensated cirrhosis, with consequent worsening of the prognosis, and concerted efforts have been made to reduce infections and improve the survival rate of these patients. We retrospectively investigated the rate of infections in hospitalized cirrhotic patients under treatment with rifaximin.
\end{abstract}

PATIENTS AND METHODS: We enrolled 649 patients whose clinical and personal data, prescribed therapy, microbiological findings and laboratory tests were collected from previous discharge letters and our institution database. The efficacy of rifaximin in preventing several types infection was evaluated by comparing outcomes for rifaximin-treated patients vs patients receiving no antibiotic treatment.

RESULTS: The risk of developing selected bacterial infections was significantly lower in patients treated with rifaximin (OR $0.29 ; 95 \% \mathrm{CI}$ $0.20-0.40, p<0.001$ ).

CONCLUSIONS: Continuous treatment with rifaximin may prevent bacterial infections in cirrhotic patients.

Key Words:

Cirrhosis, Bacterial infections, Rifaximin.

\section{Introduction}

Cirrhotic patients are prone to bacterial infections ${ }^{1}$, a leading factor in the progression from the compensated to the decompensated stage of cirrhosis ${ }^{2}$. Bacterial infections are known to lead to a fourfold increase in the probability of death in patients with advanced or decompensated cirrhosis, with a mortality rate of $30 \%$ at 1 month and of $63 \%$ at 1 year after the infection ${ }^{3}$. This proneness is multifactorial, and several studies indicate that the cirrhotic patient should be considered an immunocompromised host ${ }^{4}$.

The causes of immune dysfunction in cirrhotic patients are mainly linked to decreased bactericidal activity and low serum levels of complement factors $^{5,6}$. However, several other factors also play an important role. These include impaired reticuloendothelial system (RES) functioning. Also, in physiological conditions, the liver is the first line of defence against gut-derived pathogens through the activation of Kupffer cells, but in the cirrhotic patient, the antigen-rich portal blood is not processed by these macrophages, whose functionality is significantly compromised. The presence of portosystemic shunts, through which blood reaches the systemic circulation directly, bypassing the liver filter, is another important factor in these patients' vulnerability to infection. In addition to this, in liver cirrhosis, homeostasis between the intestinal microbiota and gut-associated lymphatic tissue is unbalanced. The prevalence of pathogens among the normal components of the intestinal flora is higher than in healthy individuals, and bacterial translocation from the intestinal lumen to mesenteric lymph-nodes has been shown in mice models ${ }^{7,8}$. Together, these factors lead to a higher rate of spontaneous bacterial peritonitis (SPB) and spontaneous bacteremia among patients affected by chronic liver disease ${ }^{9,10}$.

Norfloxacin has been advanced as a prophylactic treatment of bacterial infections in cirrhotic patients due to its high efficacy against gramnegative gut-derived bacilli ${ }^{11}$. However, the use of this class of antibiotics cannot be extensive because of the risk of selecting resistant pathogens ${ }^{12}$. We focused our research on another antibiotic proposed as an alternative to the first 
generation fluoroquinolone: rifaximin. The recent EASL position paper on spontaneous bacterial infections in cirrhosis ${ }^{13}$ stated that the efficacy and safety of this drug should be explored. As a better selection of patients who should undergo prophylactic treatment is another future goal, we retrospectively investigated the effects of this antibiotic treatment in patients with both earlystage and severe liver disease.

Rifaximin has a broad antimicrobial spectrum ${ }^{14}$ ${ }^{16}$ and nowadays is commonly used as an empirical therapy in preventing episodes of hepatic encephalopathy $(\mathrm{HE})^{17}$ : a large study published in 2010 reported that administration of this minimally-absorbed antibiotic at a dose of $550 \mathrm{mg}$ BID significantly reduces the risk of $\mathrm{HE}$ recurrences ${ }^{18}$.

The main aim of the current study is to assess the association between rifaximin prophylaxis and subsequent infection in a cohort of cirrhotic patients admitted to hospital for any reason, after adjusting for potential confounders. The secondary aim was to assess the association between rifaximin prophylaxis and rates of infection for specific sites (bloodstream infections, urinary tract infections, respiratory tract infections, skin and soft tissues infections, gastrointestinal and abdominal infections, febrile diseases, meningitis, and endocarditis) and with specific aetiologies.

\section{Patients and Methods}

This study was conducted according to the STROBE Statement indications.

(http://www.strobe-statement.org/)

\section{Study Design}

Retrospective cohort study. Cohorts were with infection vs no infection. Infectious events recorded at or during hospital admission from patient records were counted.

\section{Settings}

We examined the clinical charts of all cirrhotic patients admitted to the Division of Infectious and Tropical Diseases of the Policlinico San Matteo, in Pavia, between January 1994 and March 2014.

Our study received the approval of the Ethical Committee of IRCCS Policlinico San Matteo Pavia (Italy) for the collection and the use of patient charts for scientific publication. Because of the retrospective design, patients did not sign any specific consent but they gave their written consent to the use of clinical data for scientific use.

\section{Population}

Inclusion criteria were: age at least 18 , with HBV-related chronic hepatitis, HCV-related chronic hepatitis, HBV-HCV coinfection, HIVHCV coinfection, alcoholic cirrhosis and autoimmune cirrhosis. We collected data of patients of all cirrhotic patients admitted for any medical reasons to the Division of Infectious and Tropical Diseases of the Policlinico San Matteo, in Pavia, Italy, between January 1994 and March 2014. Subjects included in the with infection cohort were those who had had a bacterial infection at admission or during their hospital stay. Those included in the without infection cohort had been admitted for liver-related disorders other than bacterial infections. For both groups, patients who were currently on continuous Rifaximin therapy following previous admissions for hepatic encephalopathy diagnosed according to AASLD and EASL criteria (http://www.aasld.org/sites/default/files/guideline_documents/141022_AASLD_Guideline_Encephalopathy_4UFd_2015.pdf) and were included in the Rifaximin prophylaxis condition. Patients in the no prophylaxis condition were those who were not currently on antibiotic prophylaxis at the time of admission.

Criteria for diagnosis of cirrhosis were evidence of cirrhosis on laboratory or radiologic testing with or without stigmata of chronic liver disease discovered on physical examination; and/or evidence of decompensated cirrhosis, characterized by the presence of severe and lifethreatening complications such as variceal hemorrhage, ascites, or hepatic encephalopathy.

Exclusion criteria were age under 18 , liver transplantation, acute hepatitis or reacutization of chronic hepatitis during patients' stay in hospital (because of possible worsening of liver function, resulting in a sudden increase in Child or MELD score).

Liver disease stage was determined by MELD, MELD-Sodium, Child-Pugh score and the recently validated CLIF-C ADs score ${ }^{19-25}$.

\section{Variables}

Patients underwent the same diagnostic workout which is detailed below.

We collected:

- Clinical and personal data: etiology of liver disease, age, sex, days of hospitalization.

- Prescribed therapy and use of Rifaximin (all patients who had been hospitalized for previous decompensating events had also been discharged with this prophylaxis). 
- Microbiological data: Gram-positive pathogens and drug resistance.

- Laboratory tests: C-reactive protein, white blood cell count, platelet count, bilirubin, creatinine, international normalized ratio (INR), aspartate aminotransferase, alanine aminotransferase, and sodium.

The following infections were documented during the study. The diagnostic criteria adopted in our hospital are:

- Bloodstream infections: fever, positive blood culture or presence of sepsis ${ }^{26}$.

- Urinary tract infections: fever, urinary symptoms (dysuria, pollakiuria, strangury) or positive urine cultures.

- Respiratory tract infections: fever, dyspnea, chest pain or pleural effusion with compatible radiographic signs. Urine antigen results positive for Legionella pneumophila or Streptococcus pneumoniae) or positive cultures from bronchoalveolar lavage.

- Skin and soft tissue infections: physical findings (pain, tenderness, swelling, redness, warmth) on a distinct area of skin; and/or positive blood or skin cultures.

- Abdominal infections: gastrointestinal symptoms (pain, diarrhoea), fever, positive fecal culture or presence of spontaneous bacterial peritonitis $(\mathrm{SBP})^{27}$.

- Febrile diseases: fever with non-specific findings, exclusion of non-infectious aetiologies.

- Meningitis: meningeal signs, diagnostic cerebrospinal fluid test, and culture, resolution of symptoms after empiric antimicrobial therapy.

- Endocarditis: Duke criteria for infectious endocarditis $^{28}$.

- All patients with fever and ascites underwent blood culture and culture of ascites fluid.

Urine culture was performed on all patients. Urine tests for Legionella antigen and Pneumococcus were carried out where radiological signs of pneumonia were present; as well as sputum culture in some cases.

\section{Data Sources}

We collected microbiological findings, and blood analysis results from the central laboratory database of IRCCS Policlinico San Matteo, Pavia, Italy. Personal data and prescribed therapy were retrieved from discharge letters.

\section{Statistical Analysis}

Descriptive statistics were produced for demographic, clinical and laboratory characteristics of patients in the with infection group $v s$. without infection group. Mean and standard deviation (SD) are presented for normally distributed variables, and median and interquartile range (IQR) for nonnormally distributed variables, number, and percentages for categorical variables. For the patient characteristics, groups were compared with parametric or nonparametric tests, according to data distribution, for continuous variables, and with Pearson's $\chi^{2}$-test (Fisher exact test where appropriate) for categorical variables. In all cases, 2tailed tests were used. The association between infection and a number of potential explanatory variables was assessed by means of univariable and multivariable logistic regression models (taking into account repeated admissions per patient). In multivariable models, we retained clinically relevant variables or those significant at the 0.01 level at univariable analysis, excluding co-linear variables, and no further selection was carried out. Results are expressed as Odds Ratios (OR), 95\% Confidence Intervals and $p$-values.

\section{Results}

\section{Participants}

We enrolled 649 patients (232 females and 417 males), admitted a total of 1029 times over the course of the study. Mean age was 53 years (range 21 to 93). Average MELD score was 13 (range 8 to 18), MELD-Sodium 15 (range 9 to 21), Child-Pugh 9 (range 7 to 10) and CLIF score 50 (range 43 to 58 ).

Demographic and clinical characteristics of patients with and without infections are reported in Table. Decontaminating therapy with lactulose and rifaximin was administered at a standard dosage in $26.8 \%$ of admissions (276/1029). The median time on Rifaximin therapy was 57 days $\left(25^{\circ}-75^{\circ}\right.$ percentile $35-113$ days $)$. None of our patients received Norfloxacin as prophylactic therapy. We registered 410 infectious episodes (39.8\% of total hospitalizations).

Pathogens were isolated in 210 cases $(51.2 \%)$ : 102 Gram-positive bacteria, 64 Gram-negative, and both Gram-positive and Gram-negative in 22 cases. There were 21 drug-resistant species: 11 Gram-positive and 10 Gram-negative.

Factors associated to infection at univariate analyses are reported in Table I. Of note, the risk of developing bacterial infections was significantly lower in patients treated with rifaximin (OR 0.287; 95\% CI 0.202-0.407, $p<0.001$ ) compared to those not treated. 
M. Mariani, V. Zuccaro, S.F.A. Patruno, L. Scudeller, P. Sacchi, et al.

Table I. Patient data, with univariate and multivariate logistic regression analysis of factors associated with infection.

\begin{tabular}{|c|c|c|c|c|c|c|c|c|c|}
\hline \multirow[b]{2}{*}{ Variable } & \multirow{2}{*}{$\begin{array}{c}\text { Category } \\
\text { (description) }\end{array}$} & \multirow{2}{*}{$\begin{array}{c}\text { Pts } \\
\text { without } \\
\text { infection } \\
\mathbf{N}^{\circ}-\%\end{array}$} & \multirow{2}{*}{$\begin{array}{c}\text { Pts } \\
\text { with } \\
\text { infection } \\
\mathbf{N}^{\circ}-\%\end{array}$} & \multicolumn{3}{|c|}{ Univariate } & \multicolumn{3}{|c|}{ Multivariate } \\
\hline & & & & OR & $95 \% \mathrm{Cl}$ & $p$-value & OR & $95 \% \mathrm{Cl}$ & $p$-value \\
\hline \multirow[t]{2}{*}{ Prophylaxis } & No treatment & $399-64.5$ & $354-86.3$ & 1 & $1-1$ & --- & & & \\
\hline & Rifaximin & $220-35.5$ & $56-13.6$ & 0.287 & $.202-.407$ & $<0.001$ & 0.25 & $0.16-0.39$ & $<0.001$ \\
\hline \multirow[t]{5}{*}{ Age category } & $18-25$ & $3-0.48$ & $1-0.24$ & 1 & $1-1$ & --- & & & \\
\hline & $25-44$ & $147-23.8$ & $107-26.1$ & 2.184 & $.223-.21 .427$ & 0.503 & & & \\
\hline & $45-64$ & $252-40.7$ & $136-33.2$ & 1.619 & .166-15.774 & 0.678 & & & \\
\hline & $65-84$ & 205-33.1 & $147-35.9$ & 2.151 & $.22-21.016$ & 0.51 & & & \\
\hline & Over 85 & $12-1.9$ & $19-4.6$ & 4,75 & $.425-53.105$ & 0.206 & & & \\
\hline \multirow[t]{2}{*}{ Gender } & Female & $181-29.2$ & $159-38.8$ & 1 & $1-1$ & --- & & & \\
\hline & Male & $438-70.8$ & $251-61.2$ & 0.652 & $.481-.885$ & 0.006 & 0.75 & $0.51-1.08$ & 0.124 \\
\hline $\begin{array}{l}\text { Length of } \\
\text { hospitalization } \\
\text { in days }\end{array}$ & Median (IQR) & $10-(6-16)$ & $15-(10-23)$ & 1.05 & $1.034-1.065$ & $<0.001$ & 1.05 & $1.02-1.07$ & $<0.001$ \\
\hline MELD score & & 15-(11-19) & $12-(6-16)$ & 0.944 & $.922-.966$ & $<0.001$ & 0.95 & 0.93-0.97 & $<0.001$ \\
\hline MELD-Sodium & & 18-(11-24) & $14-(8-20)$ & 0.952 & $.932-.973$ & $<0.001$ & & & \\
\hline Child-Pugh & & $9-(7-10)$ & $9-(7-10)$ & 0.917 & $.833-1.01$ & 0.079 & & & \\
\hline CLIF score & & $49-(43-58)$ & $51-(43-58)$ & 1.007 & $.991-1.023$ & 0.41 & & & \\
\hline \multirow{5}{*}{$\begin{array}{l}\text { Aetiology of } \\
\text { cirrhosis }\end{array}$} & Autoimmune & 3-0.6 & 1-0.4 & 0.649 & $.067-6.288$ & 0.709 & & & \\
\hline & Alcoholic & $87-15.9$ & $40-14.2$ & 0.876 & $.573-1.338$ & 0.539 & & & \\
\hline & HBV & $39-6.3$ & $26-6.3$ & 1.007 & $.589-1.72$ & 0.98 & & & \\
\hline & $\mathrm{HCV}$ & $498-80.5$ & $288-70.2$ & 0.574 & $.413-.797$ & 0.001 & & & \\
\hline & Others & $15-2.8$ & 8-2.9 & 1.041 & $.403-2.687$ & 0.934 & & & \\
\hline \multirow[t]{6}{*}{ Comorbidities } & Diabetes & $102-18.7$ & $51-18.2$ & 0.967 & $.635-1.474$ & 0.877 & & & \\
\hline & HIV & $226-36.5$ & $157-38.3$ & 1.079 & $.798-1.46$ & 0.621 & & & \\
\hline & $\begin{array}{l}\text { Hepatocellular } \\
\text { carcinoma }\end{array}$ & $142-22.9$ & $31-7.6$ & 0.275 & $.181-.418$ & $<0.001$ & & & \\
\hline & $\begin{array}{l}\text { Multifocal } \\
\text { hepatocellular } \\
\text { carcinoma }\end{array}$ & $29-4.7$ & $10-2.4$ & 0.509 & $.228-1.133$ & 0.098 & & & \\
\hline & Solid neoplasia & $45-7.3$ & $18-4.4$ & 0.586 & $.314-1-092$ & 0.092 & & & \\
\hline & $\begin{array}{l}\text { Lymphatic } \\
\text { neoplasia }\end{array}$ & $22-3.6$ & $12-2.9$ & 0.818 & $.375-1.785$ & 0.614 & & & \\
\hline $\begin{array}{l}\text { Creatinine } \\
(\mathrm{mg} / \mathrm{dL})\end{array}$ & Median (IQR) & $\begin{array}{c}1- \\
(0.80-1.37)\end{array}$ & $\begin{array}{c}0.96- \\
(0.73-1.26)\end{array}$ & 0.975 & $.831-1.143$ & 0.752 & & & \\
\hline $\begin{array}{l}\text { Total bilirubin } \\
(\mathrm{mg} / \mathrm{dL})\end{array}$ & & $\begin{array}{c}2.73- \\
(1.61-5.64)\end{array}$ & $\begin{array}{c}1.49- \\
(0.69-3.27)\end{array}$ & 0.902 & $.859-.947$ & $<0.001$ & & & \\
\hline NR & & $1.47-(1.25-1.8)$ & $1.28-(1.1-1.54)$ & 0.732 & $.443-1.208$ & 0.222 & & & \\
\hline Sodium (mEq/L) & & 134-(131-139) & 136-(133-139) & 1.037 & $1-1.076$ & 0.047 & & & \\
\hline ALT $(\mathrm{mU} / \mathrm{mL})$ & & $56-(38-88)$ & 37-(19-63) & 0.999 & $.997-1.001$ & 0.474 & & & \\
\hline AST (mU/mL) & & $85-(52-128)$ & $49-(28-81)$ & 0.996 & $.991-1.001$ & 0.117 & & & \\
\hline $\begin{array}{l}\text { Platelet count } \\
\left(\times 10^{9} / \mathrm{L}\right)\end{array}$ & & $73.5-(51-106)$ & 121-(68-214) & 1.01 & $1.008-1.013$ & $<0.001$ & & & \\
\hline $\begin{array}{l}\mathrm{C} \text { reactive } \\
\text { protein }(\mathrm{mg} / \mathrm{dL})\end{array}$ & & $0.8-(0.32-1.8)$ & $2.49-(0.84-8.45)$ & 1.186 & $1.067-1.318$ & 0.001 & & & \\
\hline $\begin{array}{l}\text { White blood } \\
\text { cell count } \\
\text { (units } / \mathrm{mm}^{3} \text { ) }\end{array}$ & & $\begin{array}{c}4025- \\
(3030-6500)\end{array}$ & $\begin{array}{c}6870- \\
(3820-10430)\end{array}$ & 1 & $1-1$ & $<0.001$ & & & \\
\hline Deaths & $\begin{array}{l}\text { Number of } \\
\text { cases }\end{array}$ & $63-10.18$ & $26-6.34$ & 0.598 & $0.373-0.958$ & 0.033 & & & \\
\hline
\end{tabular}

Note: descriptive statistics are presented at the "admission episode" level, obtained from 649 patients with a median 1 (IQR 12, min-max range 1-10) admissions.

Table continued 
Table I (Continued). Patient data, with univariate and multivariate logistic regression analysis of factors associated with infection.

\begin{tabular}{|lccc|}
\hline Number of admissions & Frequency & Percent & Cumulative \\
\hline 1 & 470 & 72.42 & 72.42 \\
2 & 95 & 16.64 & 87.06 \\
3 & 39 & 6.01 & 93.07 \\
4 & 18 & 2.77 & 95.84 \\
5 & 9 & 1.39 & 97.23 \\
6 & 4 & 0.62 & 97.84 \\
7 & 7 & 1.08 & 98.92 \\
8 & 2 & 0.31 & 99.23 \\
9 & 4 & 0.62 & 99.85 \\
10 & 1 & 0.15 & 100.00 \\
\hline Total & 649 & 100.00 & \\
\hline
\end{tabular}

\section{Rifaximin Efficacy: Subgroup Analyses}

The association between rifaximin and specific infections is reported in Table II. The strongest protective associations were found for respiratory tract and abdominal infections.

Treatment with rifaximin showed a protective role both in patients with MELD $>15$ and in those with MELD < 15; with ORs of 0.46 (95\% CI, 0.31$0.68)$ and 0.16 (95\% CI, 0.09-0.29) respectively.

We observed (Table II) 36 bacterial identifications in the treated group (15 Gram-positive and 21 Gram-negative) vs. 174 in the non-treated group
(109 Gram-positive and 65 Gram-negative). A lower OR for Gram-positive infections was found in patients undergoing rifaximin treatment than in the non-treated group $(0.34 ; 95 \% \mathrm{CI}, .19-.60)$.

\section{Discussion}

\section{Key Results}

This work indicates that prophylactic treatment of cirrhotic patients with rifaximin is protective against bacterial infections.

Table II. Rifaximin treatment in specific infections site.

\begin{tabular}{|c|c|c|c|c|c|c|c|c|c|}
\hline \multirow[b]{2}{*}{ Variable } & \multirow[b]{2}{*}{$\begin{array}{l}\text { Category } \\
\text { (description) }\end{array}$} & \multicolumn{2}{|c|}{ Ion decontaminated } & \multicolumn{2}{|c|}{ Decontaminated } & \multirow[b]{2}{*}{ OR } & \multirow[b]{2}{*}{$95 \% \mathrm{Cl}$} & \multirow[b]{2}{*}{$\mathbf{Z}$} & \multirow[b]{2}{*}{$p>b|Z|$} \\
\hline & & $\mathbf{n}$ & $\%$ & $\mathbf{n}$ & $\%$ & & & & \\
\hline \multirow[t]{12}{*}{ Infection site } & Urinary tract & 31 & 4.1 & 14 & 5.1 & 1.24 & $.66-2.36$ & 0.671 & 0.502 \\
\hline & Abdominal & 30 & 4 & 2 & 0.7 & 0.18 & $.04-.75$ & -2.351 & 0.019 \\
\hline & Febrile disease & 37 & 4.9 & 4 & 1.5 & 0.28 & $.10-.80$ & -2.388 & 0.017 \\
\hline & Tuberculosis & 8 & 1.1 & 0 & 0 & - & - & - & - \\
\hline & Endocarditis & 10 & 1.3 & 0 & 0 & - & - & - & - \\
\hline & Meningitis & 12 & 1.6 & 1 & 0.4 & 0.23 & $.03-1.74$ & -1.428 & 0.153 \\
\hline & $\begin{array}{l}\text { Respiratory tract } \\
\text { infection }\end{array}$ & 122 & 16.2 & 9 & 3.3 & 0.17 & $.08-.37$ & -4.604 & $<0.001$ \\
\hline & Prosthesis infection & 12 & 1.6 & 1 & 0.7 & 0.24 & $.03-1.77$ & -1.419 & 0.156 \\
\hline & Abscess & 19 & 2.5 & 0 & 0 & - & - & - & - \\
\hline & Sepsis & 60 & 8 & 17 & 6.1 & 0.76 & $.43-1-33$ & -0.968 & 0.333 \\
\hline & $\begin{array}{l}\text { Atypical } \\
\text { mycobacterial } \\
\text { disease }\end{array}$ & 4 & 0.5 & 0 & 0 & - & - & - & - \\
\hline & $\begin{array}{l}\text { Skin and soft } \\
\text { tissues infection }\end{array}$ & 39 & 5.1 & 9 & 3.3 & 0.62 & $.27-1.41$ & -1.144 & 0.253 \\
\hline \multirow{3}{*}{$\begin{array}{l}\text { Microbiological } \\
\text { diagnosis }\end{array}$} & Gram-positive & 109 & 14.5 & 15 & 5.4 & 0.34 & $.19-.60$ & -3.691 & $<0.001$ \\
\hline & Gram-negative & 65 & 8.6 & 21 & 7.6 & 0.87 & $.51-1.50$ & -0.499 & 0.618 \\
\hline & $\begin{array}{l}\text { Drug-resistant } \\
\text { pathogen }\end{array}$ & 15 & 2 & 6 & 2.2 & 0.60 & $.37-3.19$ & 0.163 & 0.870 \\
\hline
\end{tabular}




\section{Rifaximin in the Non-decompensated Phase of Cirrhosis}

Rifaximin is already used to prevent and treat hepatic encephalopathy ${ }^{17,18}$, a commonly occurring complication in the decompensated phase of cirrhosis $^{2}$ : for this reason, it is mainly adopted in patients with a high MELD score (13-15 or more). Our findings suggest that Rifaximin also gives outstanding benefits in non-decompensated cirrhosis; and that we should, therefore, consider starting this treatment independently of liver impairment stage.

\section{Efficacy of Rifaximin in Protecting Against Specific Infections}

Intestinal decontamination was protective to some degree against all specific infection types (see Table II). Nevertheless, abdominal and respiratory tract infections and febrile diseases were significantly less frequent in treated than in nontreated patients, suggesting that rifaximin had a particularly strong impact on these infections. The abdomen was a common infection site in our patients. However, of 32 episodes in 30 cases, only 2 occurred in patients who had undergone intestinal decontamination. This is noteworthy, given that SPB is one of the most frequent clinical challenges in cirrhotic patients.

The effects for sepsis and urinary tract infections were not significant, but the data are suggestive: of 77 episode of sepsis, 60 occurred in the non-decontaminated group and only 17 in decontaminated patients. We observed a similar trend for urinary tract infections: of a total of 45 episodes, 31 occurred in decontaminated and 14 in non-decontaminated patients.

\section{Interpretation of the Results}

The success of Rifaximin antibiotic prophylaxis could depend on its strong effectiveness against Gram-positive and Gram-negative gut-derived bacteria ${ }^{16,29}$. Indeed, this rifamycin-derivate reaches a high concentration in the gastrointestinal tract and has minimal systemic bioavailability. Given its demonstrated role in reducing ammonia-producing enteric bacteria, rifaximin could be effective against pathogens commonly involved in cirrhosis-related infections: E. coli, Shigella, Salmonella, Staphylococcus spp, Streptococcus spp, and Enterococcus spp.

In these patients, infectious events are common because of increased intestinal permeability and cirrhosis-associated immune dysfunction (CAID). Continuative treatment with rifaximin could maintain a low bacterial count or even eradicate gut-growing pathogens, leading to less intense bacterial translocation ${ }^{13}$. Therefore, in patients with small intestine bacterial overgrowth (SIBO) syndrome, rifaximin should be considered to improve symptom severity ${ }^{30}$.

One interesting finding was that rifaximin is a risk factor for the development of a Gram-negative infection. Differences in microbial prevalence between treated and non-treated patients have also been described in other studies ${ }^{31}$. Consideration of the in-vitro and in-vivo efficacy of this antibiotic suggests the reason for this only partially unexpected behaviour: fecal levels of rifaximin are very high, reaching 4000-8000 $\mu \mathrm{g} / \mathrm{g}$ stool $^{32}$, making this drug remarkably effective against both Gram-positive and Gram-negative bacteria. However, in another in-vitro study, the $\mathrm{MIC}_{50}$ of rifaximin appeared to be much lower for Gram-positive than for Gram-negative bacteria $(<0.015-2 \mu \mathrm{g} / \mathrm{ml}$ for Gram-positive; $12.5-128$ $\mu \mathrm{g} / \mathrm{ml}$ for Gram-negative $)^{33}$. This different susceptibility could induce changes in intestinal microbiota and account for the difference in bacterial aetiologies in treated versus non-treated patients. Interesting data in support of the rifaximin-induced changes in intestinal microbiota was described in an interesting study of Ciobanu et $\mathrm{al}^{34}$ : they considered that rifaximin could limit necroinflammatory lesions determined by NSAIDs on guinea pig small bowel.

Physicians choosing an empirical antibiotic therapy for cirrhotic patients who have undergone long-term rifaximin treatment should consider this finding.

The positive correlation at the univariate analysis of infectious events with lower but not with higher MELD scores is to be explained by the characteristics of our population: admission of patients with the less severe liver disease was more likely to be related to external decompensating factors, among which infections play a major role. On the other hand, patients with advanced cirrhosis were usually hospitalized and died of complications related to the underlying liver disease (i.e. encephalopathy, variceal bleeding, ascites).

\section{Study Limitations}

We collected data on hospitalized patients retrospectively. One limitation of this type of study is that not all biological and clinical data are available for some patients. We also enrolled only hospitalized patients and with the available data we could not differentiate between those admitted 
because of an infectious event and those who developed infections during their hospital stay. No follow-up was possible, also because of the retrospective design of the study and because access to patient data was limited to what was available in our hospital. For this reason, the long-term outcome of patients is beyond the aim of the study.

\section{Conclusions}

Long-term treatment with rifaximin may be an effective tool in the prevention of bacterial infections in cirrhotic patients. The protective effect seems to be present for every etiology and stage of cirrhosis, but varies for different types of infections. As a prophylaxis, rifaximin may reduce the rate of hospitalization of patients with liver disease and lead to a global shortening of hospital stay.

\section{Acknowledgements}

We are indebted to Claire Archibald for the careful English editing and to Riccardo Albertini, MD for assistance with data extraction

\section{Conflict of Interest}

The Authors declare that there are no conflicts of interest.

\section{References}

1) Borzio M, Salerno F, Piantoni L, Cazzaniga M, ANGeli P, Bissoli F, Boccia S, Colloredo-Mels G, Corigliano P, Fornaciari G, Marenco G, Pistarà R, SALVAGNINI M, SANGIOVANNI A. Bacterial infection in patients with advanced cirrhosis: a multicentre prospective study. Dig Liver Dis 2001; 33: 41-48.

2) d'Amico G, Garcia-Tsao G, Paglaro L. Natural history and prognostic indicators of survival in cirrhosis: a systematic review of 118 studies. J. Hepatol 2006; 44: 217-231.

3) Arvaniti V, D'Amico G, Fede G, Manousou P, Tsochatzis E, Pleguezuelo M, Burroughs AK. Infections in patients with cirrhosis increase mortality four-fold and should be used in determining prognosis. Gastroenterology 2010; 139: 1246-1256.

4) TANDON $P$, GARCIA-TSAO G. Bacterial infections, sepsis, and multiorgan failure in cirrhosis. Semin Liver Dis 2008; 1: 26-42.

5) Fierer J, Finley F. Deficient serum bactericidal activity against Escherichia coli in patients with cirrhosis of the liver. J Clin Invest 1979; 63: 912921.
6) Hassner A, Kletter $Y$, Shlag D, Yedvab M, Aronson M, SHIBOLET S. Impaired monocyte function in liver cirrhosis. Br Med J 1981; 282: 1262-1263.

7) Berg RD, GarLington AW. Translocation of certain indigenous bacteria from the gastrointestinal tract to the mesenteric lymph nodes and other organs in a gnotobiotic mouse model. Infect Immun 1979; 23: 403-411.

8) Chen Y, Yang F, lu H, Wang B, Chen Y, Lei D, WANG Y, ZHU B, LI L. Characterization of fecal microbial communities in patients with liver cirrhosis. Hepatology 2011; 54: 562-572.

9) Lahnborg G, Friman L, Berghem L. Reticuloendothelial function in patients with alcoholic liver cirrhosis. Scand J Gastroenterol 1981; 16: 481489.

10) Rimola A, Soto R, Bory F, Arroyo V, piera C, Rodes J. Reticuloendothelial system phagocytic activity in cirrhosis and its relation to bacterial infections and prognosis. Hepatology 1984; 4: 53-58.

11) Fagiuol $S$, Colli $A$, Bruno R, Burra $P$, Craxi $A$, Gaeta GB, Grossi P, Mondelli MU, Puoti M, Sagnelli E, Stefani S, TONIUTTO P. Management of infections in cirrhotic patients: report of a Consensus Conference. Dig Liver Dis 2014; 46: 204-212.

12) Fernández J, NAVAsa M, Gómez J, Colmenero J, Vila $\mathrm{J}$, ARROYo V, RodÉs J. Bacterial infections in cirrhosis: epidemiological changes with invasive procedures and norfloxacin prophylaxis. Hepatology 2002; 35: 140-148.

13) Jalan R, Fernandez J, Wiest $R$, Schnabl $B$, Moreau R, Angel P, Stadlbauer $V$, Gustot T, Bernardi $M$, Canton R, Albillos A, Lammert F, Wilmer A, Mookerjee R, Vila J, Garcia-Martinez R, Wendon J, Such $J$, Cordoba J, Sanyal A, Garcia-Tsao G, Arroyo V, BURROUGHS A, GinĖs P. Bacterial infections in cirrhosis: a position statement based on the EASL Special Conference 2013. J Hepatol 2014; 60: 1310-1324.

14) Debbia EA, Maioli E, Roveta S, Marchese A. Effects of rifaximin on bacterial virulence mechanisms at supra- and sub-inhibitory concentrations. J Chemother 2008; 20: 186-194.

15) Gerard L, Garey KW, DuPont HL. Rifaximin: a nonabsorbable rifamycin antibiotic for use in nonsystemic gastrointestinal infections. Expert Rev Anti Infect Ther 2005; 3: 201-211.

16) Hoover WW, Gerlach EH, Hoban DJ, Elopoulos GM, Pfaller MA, Jones RN. Antimicrobial activity and spectrum of rifaximin, a new topical rifamycin derivative. Diagn Microbiol Infect Dis 1993; 16: 111-118.

17) Prakash R, Mullen KD. Mechanisms, diagnosis and management of hepatic encephalopathy. Nat Rev Gastroenterol Hepatol 2010; 7: 515-525.

18) Bass NNM, Mullen KKD, SANyal A, Poordad F, Neff G, Leevy CB, Sigal S, Sheikh My, Beavers K, Frederick T, Teperman L, Hillebrand D, Huang $S$, MERCHANT K, ShAW A, Bortey E, Forbes WP. Rifaximin treatment in hepatic encephalopathy. $\mathrm{N}$ Engl J Med 2010; 362: 1071-1081. 
19) FORMAN LM, LUCEY MR. Predicting the prognosis of chronic liver disease: an evolution from child to MELD. Mayo End-stage Liver Disease. Hepatology 2001; 33: 473-475.

20) Borroni G, Maggi A, Sangiovanni A, Cazzaniga M, SALERNO F. Clinical relevance of hyponatraemia for the hospital outcome of cirrhotic patients. Dig Liver Dis 2000; 32: 605-610.

21) Infante-Rivard C, Esnaola S, Villeneuve JP. Clinical and statistical validity of conventional prognostic factors in predicting short-term survival among cirrhotics. Hepatology 1987; 7: 660-664.

22) KAMATH PS, KIM WR. The model for end-stage liver disease (MELD). Hepatology 2007; 45: 797-805.

23) KIM WR, BIgGins SW, KREMERS WK, WIESNER RH, KAmath PS, Benson JT, EDwards E, Therneau TM. Hyponatremia and mortality among patients on the liver-transplant waiting list. N Engl J Med 2008; 359: 1018-1026.

24) Malinchoc M, Kamath PS, Gordon FD, Peine CJ, Rank J, TER BORG PC. A model to predict poor survival in patients undergoing transjugular intrahepatic portosystemic shunts. Hepatology 2000; 31: 864-871.

25) Jalan R, pavesi M, Saliba F, Amorós A, Fernandez J, Holland-Fischer $P$, SAWHney $R$, MookerJee $R$, Caraceni P, Moreau R, Ginės P, Durand F, Angel P, Alessandria C, Laleman W, Trebicka J, Samuel D, Zeuzem S, Gustot T, Gerbes AL, Wendon J, Bernardi M, ARROYO V; CANONIC STUDY INVESTIGATORS; EASLCLIF Consortium. The CLIF Consortium Acute Decompensation score (CLIF-C ADs) for prognosis of hospitalised cirrhotic patients without acute-onchronic liver failure. J Hepatol 2014; 62: 831-840.

26) Dellinger RP, Levy Mm, Rhodes A, Annane D, Gerlach H, Opal SM, Sevransky Je, Sprung CL, Douglas IS, Jaeschke R, Osborn tM, Nunnally ME, TOWNSENd SR, Reinhart K, KLEINPELl RM, Angus DC, DeUtSCHMAN CS, MACHADO FR, RUBENFELD GD, WebB S, Beale RJ, Vincent Jl, Moreno R; Surviving Sepsis
Campaign Guidelines Committee including The PediATRIC SUBGROUP. Surviving Sepsis Campaign: international guidelines for management of severe sepsis and septic shock, 2012. Intensive Care Med 2013; 39: 165-228.

27) Ginès P, Angeli P, Lenz K, Møller S, Moore K, Moreau R, Merkel C, Ring-Larsen H, Bernardi M. EASL clinical practice guidelines on the management of ascites, spontaneous bacterial peritonitis, and hepatorenal syndrome in cirrhosis. $\mathrm{J}$ Hepatol 2010; 53: 397-417.

28) DURACK DT, LUKES AS, BRIGHT DK. New criteria for diagnosis of infective endocarditis: utilization of specific echocardiographic findings. Am J Med 1994; 96: 200-209.

29) Sierra JM, Ruiz J, NaVia MM, Vargas M, Gascon J, VILA J. In vitro activity of rifaximin against enteropathogens producing traveler's diarrhea. Antimicrob Agents Chemother 2001; 45: 643-644.

30) Di Stefano M, Miceli E, Missanell A, Corazza Gr. Treatment of small intestine bacterial overgrowth. Eur Rev Med Pharmacol Sci 2005; 9: 217-222.

31) Lutz P, Parcina M, Bekeredjian-Ding I, Nischalke hD, Nattermann J, Sauerbruch T, Hoerauf A, StrassbuRg CP, SPENGler U. Impact of rifaximin on the frequency and characteristics of spontaneous bacterial peritonitis in patients with liver cirrhosis and ascites. PLoS One 2014; 9: e93909.

32) ADACHI JA, DuPONT HL. Rifaximin: a novel nonabsorbed rifamycin for gastrointestinal disorders. Clin Infect Dis 2006; 42: 541-547.

33) JIANG ZD, DuPONT HL. Rifaximin: in vitro and in vivo antibacterial activity a review. Chemotherapy 2005; 51 Suppl 1: 67-72.

34) Ciobanu l, taulescu M, Prundus R, Diaconu B, andreica V, Catol C, pascu O, Tantau M. Effects of rifaximin on indomethacin-induced intestinal damage in guinea-pigs. Eur Rev Med Pharmacol Sci 2014; 18: 344-351. 